\title{
A Patologia na Trilha Que une a Morfologia Tradicional à Medicina de Precisão
}

\author{
Fernando Augusto Soares ${ }^{n}$
}

\begin{abstract}
a Professor Titular da Disciplina de Patologia Geral, Faculdade de Odontologia da Universidade de São Paulo e Diretor Médico da Anatomia Patológica da Rede D’Or São Luiz. Unidade Jabaquara, Rua das Perobas 266, São Paulo, SP. CEP 04321-120. E-mail fernando.asoares@rededor.com.br
\end{abstract}

\section{Resumo}

O desenvolvimento da patologia, uma das ciências médicas mais antigas e consolidadas, tem cerca de sete séculos. Essa longa jornada iniciou com os grandes anatomistas. Toda a evoluçấo da medicina na idade média esteve associada ao conhecimento gerado pelas autopsias, chamada na época de anatomia mórbida. O advento da patologia celular, no final do século XIX, mudou totalmente a classificação das neoplasias e permitiu o desenvolvimento da patologia cirúrgica. $\mathrm{O}$ advento dos biomarcadores permitiu uma grande mudança, passando dos diagnósticos axiomáticos para diagnósticos baseados em evidências de expressão proteica, análise de transcritos de RNA e alteraçóes na sequência de DNA. O advento da patologia molecular, já no século XXI, transforma novamente a patologia e cria o desafio da formação da nova geração de patologistas. $\mathrm{O}$ presente artigo analisa de forma resumida o caminho trilhado pela patologia em seu desenvolvimento ao longo desses 700 anos.

\section{Palavras-chave}

Patologia Cirúrgica, Patologia Molecular, Anatomia Patológica, Diagnóstico Morfológico

\section{Abstract}

The development of pathology, one of the oldest and most consolidated medical sciences, is about seven centuries old. This long journey began with the great anatomists. The entire evolution of medicine in the Middle Ages was associated with the knowledge generated by autopsies, called morbid anatomy at the time. The advent of cellular pathology, at the end of the 19th century, totally changed the classification of neoplasms and allowed the development of surgical pathology. The advent of biomarkers allowed a great 
change, moving from axiomatic diagnoses to diagnoses based on evidence of protein expression, analysis of RNA transcripts and changes in the DNA sequence. The advent of molecular pathology, already in the 21 st century, again transforms pathology and creates the challenge of training the new generation of pathologists. This article briefly analyzes the path taken by pathology in its development over these 700 years.

\section{Keywords}

Surgical Pathology, Molecular Pathology, Pathological Anatomy, Morphological Diagnosis

\section{A trilha da Morfologia - DA ANATOMIA MÓRBIDA À PATOLOGIA CELULAR}

A patologia como ciência e a arte de praticar medicina são um uníssono desde o século XIV. Os grandes tratados da medicina antiga tinham como base a anatomia mórbida, ou seja, entender as doenças através das alteraçôes observadas durante a autópsia. A autópsia se iniciou no século XII, juntamente com as grandes Universidades Europeias $^{1}$. A igreja católica, embora não proibisse a dissecção de corpos humanos, não a recomendava. Entretanto os clérigos eram proibidos de ter este tipo de atividade conforme determinado pelo papa Alexander III na diretiva "Ecclesia abhorret a sanguine" Esta encíclica foi interpretada que clérigos não poderiam, portanto, praticar cirurgias ou dissecçóes, uma vez que estariam em contato com sangue ${ }^{2}$. Entretanto, a prática seguiu nas Universidades quando o imperador do Império Romano Frederico II tornou compulsório para todos que praticassem medicina a análise de um corpo humano a cada cinco anos. Um novo revés no uso da autópsia ocorreu quando o papa Bonifácio VIII publicou a encíclica "De Sepolturis", onde proibia a manipulação de corpos humanos. Mas, incrivelmente, a Universidade de Bologna faz uma dissecção pública em 1315 , em um corpo de uma criminosa e isto marca a volta do estudo da anatomia. Esse fato contou com a conivência do Imperador Frederico II e do Papa Nicolas II e as Universidade Italianas tornaram-se o centro dos grandes anatomistas. Universidades como as de Perugia, Pádua e Florença tornam obrigatória a autopsia para que seus estudantes recebam o grau de doutor em medicina. Grandes nomes da medicina, tais como Antônio Benevieni ("De Abtidis...Morborum...Causis') e Andreas Vesalius ("De Humanis Corporis Fabrica”, florescem. É interessante ressaltar que diversos artistas da época (entre eles Leonardo da Vinci) realizam autópsias com o intuito de conhecer o corpo humano e dar mais realismo às suas obras. Nesta época há diversos relatos de como os corpos eram "roubados" pelos estudantes e o Vesalius foi 
acusado de práticas antiéticas e até mesmo de ter realizado uma autópsia em um corpo ainda em vida ${ }^{1}$. Finalmente, toda a polêmica foi encerrada na Europa no final do século XVI (1556) após um concilio realizado na faculdade de Teologia da Universidade de Salamanca onde a Igreja Cristá permitiu o estudo do corpo humano desde que com intuito "científico". Diz a decisão que a dissecção de corpos humanos, desde que com serventia a propósitos úteis, é permitida para cristáos da Igreja Católica ${ }^{3}$.

Agora entáo a Patologia floresce como ciência e o entendimento das doenças a partir das alteraçóes anatômica passa a ser a rotina, em uma ciência conhecida como anatomia mórbida. Giovanni Batista Morgagni ("De Sebitus et Causis Morborum per Anatomen Indagatis') publica em 1761 os dados referentes a 640 autópsias, Mattew Baillie escreve em 1793 o livro "The morbid anatomy of some of the most important parts of the human body", Francois Bichat traz a ideia dos tecidos no livro (1802) "Traité des membranes en général et de diverses membranes en particulier" e pela escola austro-germânica Carl Rokitansky que escreveu a famosa oração ao cadáver desconhecido que pode ser encontrada pelas salas de autopsia mundo afora ${ }^{3}$. E o resumo disso tudo foi eternizado por Rembrandt que retrata Nicolaes Tulp ensinando aspectos dos músculos no famoso quadro "Anatomy Lesson”.

\section{A grande mudança da Anatomia Mórbida para a Patologia Celular}

Após quase seis séculos de desenvolvimento da anatomia mórbida e a patologia, uma revoluçáo ocorreu no final do século XIX. Como quase tudo em medicina a adição tecnológica antecipou o conhecimento científico. Ao final do século XVII e inicio do século XVIII surgem, quase que simultaneamente, os microscópios. Isso permite que os primeiros microanatomistas sejam reconhecidos, com destaque para Marcello Malpighi que estabeleceu as bases da histologia ${ }^{4}$. Novamente a tecnologia se impóe com a invenção do micrótomo, que permitiu cortes sequencias e finos, o desenvolvimento dos químicos fixadores do tecido e as coloraçôes básicas como a hematoxilina e $\operatorname{eosina}^{6,7}$. Esses desenvolvimentos da histologia podem ser resumidos na premiação Nobel de Camillo Golgi e Santiago Ramón y Cajal, por suas contribuiçóes no conhecimento da estrutura do sistema nervoso ${ }^{8}$. Isso coincide com a introdução na medicina do estetoscópio e esfigmomanômetro, descobertas angulares na clínica médica.

Nesse cenário surge a figura de Rudolph Virchow ${ }^{9}, 10$. Baseado em conhecimentos desenvolvidos pelo botânico Mathias Scheleiden, no meio do século XIX, que levaram a Theodor Schwann a emitir o conceito de que "todos os elementos vivos são compostos por células e produtos celulares", Virchow 
estabeleceu uma nova era na patologia. A partir de estudos extensivos ao microscópio, ele criou a teoria que os tumores se iniciam em locais de inflamação e que isso levaria as células a proliferar. Isso levou à publicação do ensaio "Omnis cellula e cellula" e do livro seminal "Die cellularpathologie", nome que deu lugar ao reconhecimento de uma era de 100 anos de desenvolvimento do conhecimento. Esse grande avanço da patologia na Europa levou que a medicina norte-americana ganhasse corpo e passasse a se interessar por uma ciência que ficou reconhecida como patologia cirúrgica.

Depois disso, temos que entender a trilha do caminho da morfologia em conjunto com a evolução das especialidades médi$\operatorname{cas}^{5}$. Se, no início, a cirurgia e anatomia se confundiam, nesse momento a cirurgia e a patologia se sobrepunham. Um avanço significativo foi a introdução do diagnóstico intra-operatório através dos cortes de congelação $^{11}$. Essa talvez seja a primeira contribuição efetiva da patologia norte-americana e os primeiros grandes patologistas cirúrgicos como Willliam Welsh, Thomas Cullen e Louis Wilson, que passaram a defender o diagnóstico per-operatório. Com isso, surge essa especialidade híbrida, tendo o primeiro exame para especialista em patologia ocorrido em 1936 com a fundação do American Board of Pathology.

Durante todo o século XX houve o desenvolvimento da histopatologia, patolo- gia cirúrgica e a classificação das doenças. A patologia passou a ter um papel seminal na Oncologia pois todos os tratamentos estão baseados no aspecto morfológico. Fez-se necessário, então, a criação de um grupo de patologistas cirúrgicos eminentes pois a interpretação dos preparados histopatológicos é revestida de grande subjetividade... ou era!

Um primeiro passo para a objetividade foi a invenção do microscópio eletrônico ${ }^{12}$. Através da ultraestrutura podíamos identificar a organização e tipo de organelas em cada tipo de tecido e sua composição/distribuição. Dessa forma, o achado de um semi-desmossomo em um tumor indiferenciado fazia dele um carcinoma, sem lugar para discussões baseadas em subjetividade. Entretanto, os microscópios eletrônicos eram caros, de difícil manutenção e com poucos especialistas no mundo. Portanto seu uso disseminado no dia a dia do diagnóstico foi sempre restrito a poucas instituiçóes e poucas áreas da patologia. Ainda hoje segue tendo sua utilidade em situaçóes especiais como a nefropatologia e patologia muscular, apesar da incontestável importância nas descobertas científicas.

A grande revolução na patologia cirúrgica iniciou-se ao final da década de 50 com a imunofluorescencia e se consolidou na década de 80 com o advento da imuno-histoquímica. Iniciamos então a era da objetividade com os biomarcadores ${ }^{13}$. 
Os BIOMARCADORES E A REVOLUÇÃo

da Patologia Cirúrgica AO FINAL do SÉCUlo XX

O patologista em sua prática diária faz uso das alteraçóes arquiteturais teciduais para estabelecer padróes e concluir o diagnóstico de uma doença. Quando consideramos o dogma central da biologia, o patologista se vale da arquitetura das milhares de proteínas que definem uma célula, como estas se organizam e formam o tecido são ou doente. Não creio que tivéssemos, há alguns anos, a consciência de pensar a observação microscópica com olhos da biologia celular. Quando muito, a figura de mitose era o mais próximo que chegávamos dos aspectos básicos. Livros de patologia celular e molecular não faziam parte da estante do patologista cirúrgico e, quando muito, havia um livro de patologia geral cujos primeiros seis ou sete capítulos tratavam dos mecanismos básicos da doença. Mesmo assim, esses capítulos eram muito mais apreciados pelos patologistas acadêmicos do que aqueles afeitos ao diagnóstico cirúrgico.

Com a evolução da medicina e dos tratamentos alvo-específicos, uma nova forma de entender os aspectos biológicos e sua importância no diagnóstico foram criados. $\mathrm{O}$ dogma da biologia celular de que uma molécula de DNA faz a transcrição em uma molécula de RNA e que esta se traduz em proteínas passou a ser fator fundamental para se enten- der a medicina de precisão. $\mathrm{O}$ patologista no seu hábito de como analisar os tecidos tem um quarto elemento, que é a arquitetura que permite o diagnóstico. É natural se pensar que o patologista vai olhar o dogma central da biologia no seu reverso. Assim, a figura que observo no microscópio é decorrente do conjunto de proteínas, que foram traduzidas a partir de uma molécula de RNA, que por sua vez foi transcrita a partir da molécula de DNA. Essa distinção sutil faz toda a diferença na conversa biologia-patologia e somente isso pode motivar um patologista a entender as biologias celular e molecular. Então, a decorrência mais imediata (intuitiva?) é que o mundo dos biomarcadores se iniciasse pelas proteínas e não pelo sequenciamento do DNA. Os setecentos anos de desenvolvimento do raciocínio anatomopatológico passou a ser desafiado pelos sessenta anos de entendimento do dogma central.

As proteínas permitem uma identificação com certa facilidade. Lógico é que, se fossemos buscar seu reconhecimento pela estrutura e conformação espacial, seria extremamente complicado. Mas como são antigênicas, a criação de anticorpos anti-epitopos específicos para serem usados no laboratório é relativamente fácil. A evolução técnica foi relativamente rápida e já na década de 80 tínhamos anticorpos suficientes para identificar os tumores e hoje um laboratório de patologia cirúrgica tem em seu elenco diagnóstico por volta de 400 diferentes proteínas a serem testadas. 
Daí a continuar no passeio do dogma central reverso vieram as técnicas de hibridação in situ para o reconhecimento dos transcritos de RNA (especialmente em identificação de transcritos de agentes virais) e de alterações cromossômicas. Isso tudo em um espaço de 15 anos e hoje completamente consolidado na prática diária. Mas a demanda da medicina de precisão exigiu mais ainda dos laboratórios de patologia e do patologista diagnóstico.

A genômica ganhou o seu espaço no século XXI. O sequenciamento completo do genoma humano em 2001 trouxe a possibilidade técnica de buscarmos o diagnóstico na sequencia do DNA e suas alteraçóes por mutaçóes. A possibilidade de testarmos muitas alterações de uma só vez faz com que o perfil molecular dos tumores seja conhecido e que os oncologistas tenham múltiplas opçóes dentro do que hoje é conhecido como medicina de precisão, tratamento alvo-específico, medicina personalizada ou taylored-medicine. Não existe uma definição precisa para tal e, na essência, é a abordagem da prevenção e tratamento das doenças levando em conta a variabilidade das alteraçóes genéticas, do meio ambiente e do estilo de vida de cada indivíduo.

\section{BIOMARCADORES: OS USOS E ABUSOS}

O termo "biomarcador" é hoje amplamente utilizado e muitas vezes depende do contexto onde ele é inserido. Por definição, biomarcador é uma informação objetiva de um estado médico percebido no paciente e que pode ser medido acuradamente e de forma reprodutível ${ }^{13}$. Os sintomas percebidos e relatados pelos pacientes não se encaixam na definição, mas os próprios sinais de uma doença podem ser considerados como biomarcadores. Em outras palavras, um biomarcador é qualquer medida que reflita a interação entre um sistema biológico e um potencial risco para o paciente. $\mathrm{O}$ elemento mesurável pode ser fisiológico, bioquímico, a nível celular ou uma interação molecular. A medida de pulso e da pressão arterial são marcadores. Neste texto fazemos um abuso da definição e os restringimos aqueles que podem ser medidos na prática da patologia.

Para a patologia estamos obviamente limitados àqueles indicadores que possam ser medidos no laboratório e, mais especificamente, nos tecidos. Deixamos aqueles biomarcadores em fluídos para a medicina laboratorial. Todas as alteraçóes genéticas são biomarcadores em potencial. Nelas estão incluídas as variaçôes na sequência do DNA (mutações pontuais), as translocações e os genes de fusão, as variaçóes no número de cópias (deleções, duplicaçôes, amplificaçôes, perda de heterozigocidade), as alteraçóes epigenéticas e como estas todas se traduzem nas proteínas dos tecidos. Hoje temos anticorpos que detectam proteínas codificadas por genes mutados ou a perda de função destas com grande precisão. 
O grande desejo de todos que participam dessa evolução é que tenhamos biomarcadores precisos e polares; uma resposta do tipo sim/não ${ }^{14}$. Realmente alguns são assim; como uma alteração patogênica na sequencia no gene TP53 e que faz parte da definição a síndrome de Li-Fraumeni. Mas, mesmo assim, necessitamos de todo um contexto clinico nessa avaliação. Mas a grande maioria dos marcadores está em um espectro de especificidade que sempre necessita a avaliação parcimoniosa. Não basta determinar um perfil de proteínas para a definição do diagnóstico. A avaliação parcimoniosa dos resultados em conjunção com os aspectos clínicos-epidemiológicos é mandatória.

Muito temos aprendidos quando fazemos um vai-e-volta no dogma central. $\mathrm{Ou}$ seja, enquanto patologista vamos observar os achados morfológicos, marcar proteínas, transcritos ou sequencias. Mas, uma vez feito está caminho, agora somos capazes de inferir as alteraçóes moleculares com um corte histológico. Por exemplo quando um patologista observa um carcinoma de mama bem delimitado, formação tubular pobre, com muitos linfócitos dentro do tumor, grau nuclear alto e muitas mitoses tem quase a certeza de que se trata de um carcinoma ductal do tipo triplo negativo. Os exemplos são muitos pois vamos aprendendo cada vez mais com o desenvolvimento do conhecimento e isto torna a patologia cirúrgica mais atual. $\mathrm{O}$ fascinante é que este exercício pode ser ampla- mente feito em um país com as dificuldades do Brasil, uma vez que a patologia morfológica tradicional está disponível em qualquer centro e por um custo muito pequeno.

Os biomarcadores em patologia cirúrgica pertencem a três categorias: diagnósticos, prognósticos e/ou preditivos ${ }^{15,16}$.

Os marcadores diagnósticos são aqueles que permitem identificar uma doença ou um subtipo tumoral. Desde o advento da imuno-histoquímica que esses são utilizados para o diagnóstico diferencial entre neoplasias pouco diferenciadas. Os patologistas já usam esses exemplos desde a década de 80 e o desenvolvimento desse tipo de marcador continua. Há muita sobreposição e por esta razão geralmente se usa um conjunto de combinaçóes proteicas mais ou menos específicas para cada tipo de tumor.

Os marcadores prognósticos são utilizados para identificar a potencial história natural da doença. Com isso, identificamos alguns tipos especiais de tumores que devem ser sacados do grande grupo definido pela topografia e histopatologia para que idealmente medidas terapêuticas específicas permitam a mudança daquele curso natural. Esse uso tem sido amplamente substituído à medida que terapias marcadores-dirigidas são implantadas.

Os marcadores preditivos são aqueles que nos indicam se determinada doença irá responder a um determinado tratamento. Não há nenhum sentido na implantação da 
medicina de precisão, se o uso dos remédios continua amplo. Desta forma, idealmente, um marcador preditivo deve estabelecer o melhor tratamento e a quantificação mais aproximada possível do índice de resposta. Neste sentido, esses podem ser marcadores positivos (quando a presença indica uma droga-específica), podem ser negativos (quando contraindicam a droga) ou dualísticos (onde, dependendo da alteração, podem indicar ou não a droga e potencialmente o esquema terapêutico).

Como usamos e qual o tipo de técnica a ser utilizada cabe ao trinômio especificidade-sensibilidade-custo. Cabe ao patologista de hoje entender as demandas e limitações de cada teste. Outro fator nessa equação é a janela de tempo no resultado emitido. Por vezes temos um teste que é extremamente informativo, mas que demanda tempo e tem grande custo versus outro menos sensível, mas barato e rápido. Essas variáveis só podem ser avaliadas na correlação clínico-patológica.

Quando e como escolhemos o teste a ser usado? Muitas vezes os testes são redundantes e podem apresentar a mesma efetividade. A imuno-histoquímica é hoje um teste barato e que pode ser entregue em menos de 24 horas ao paciente. Algumas vezes pode ter menor especificidade, mas em muitas ocasióes é tão seguro quanto o sequenciamento do exoma. As técnicas de hibridação in situ são mais trabalhosas, exigem expertise maior do laboratório e do patologista e são mais caras, mas podem ser o teste de eleição, como por exemplo, para translocaçóes e amplificaçóes cromossômicas. $\mathrm{O}$ teste molecular pode ser tấo simples quanto a detecção de uma variação na sequencia e pode ser ampla como determinar as diversas alterações no genoma. Podem ser painéis específicos para um tipo de tumor ou painéis amplos com a detecção de centenas de potenciais alvos genômicos. Tais testes ora são melhores no tumor original, ora no material das metástases. Podem ter materiais que não se prestam a eles e depende muito de como o material foi preservado. Em resumo, não existe fórmula pronta e cada situação deve ser amplamente discutida com a equipe médica.

\section{NosSOS VELHOS PROBLEMAS}

Todas essas mudanças ocorreram em um cenário de patologia tradicional, de baixa formação de jovens patologistas e em um tempo extremamente curto quando se fala de ciência. E assim é hoje. $\mathrm{O}$ conhecimento, especialmente em Oncologia, duplica em velocidade estonteante. Temos muitos problemas nesse desenvolvimento como as dificuldades das Universidades, a baixa seleção dos estudos na internet, a falta de reprodução de resultados e a falta de comunicação efetiva. Há um abismo separando a descoberta científica da aplicação clínica. Os problemas da 
Speed Science ficaram evidentes nesta atual pandemia COVID-19.

Mas, em termos de diagnóstico em patologia, temos problemas para aplicação da patologia de precisão. $\mathrm{O}$ desenvolvimento dos centros de patologia não se dá de forma homogênea no país e temos que conviver com diferentes realidades. Ainda temos problemas técnicos primários como o uso de fixadores inapropriados para os testes genéticos, a falta de padronização dentro do laboratório, diversos problemas na análise do material e problemas pós-analíticos como a guarda totalmente inapropriada do bloco de parafina. Não há controle do tempo de isquemia fria e tampouco do tempo de fixação. Esses fatores contribuem para o sucesso ou falha do teste molecular.

A grande maioria dos laboratórios no País ainda carece de padronização, controle e procedimentos redundantes. Há pouco controle pelos órgãos regulatórios e nossas legislaçôes estão totalmente defasadas, preocupadas mais com as aspectos absolutamente cosméticos do que com os funcionais. $\mathrm{O}$ treinamento nas residências segue ainda um modelo tradicional preparando muito pouco a nova geração para essa medicina diferente. $\mathrm{O}$ modelo de educaçáo continuada atinge poucos patologistas e geralmente sempre a mesma população que já está atenta às mudanças.
O material e a abordagem dos tumores também mudaram. Hoje cada vez se faz procedimentos com a coleta de pequenas biopsias, como as intervençóes para material obtido por agulha. Há dez anos atrás seria inconcebível se fazer o diagnóstico de um linfoma que náo pela excisão do linfonodo suspeito, enquanto que hoje a biopsia por agulha é a regra. $\mathrm{O}$ paradoxo está que em um pequeno material temos que fazer os biomarcadores diagnósticos, para que, depois deste firmado, passemos aos biomarcadores preditivos. Ou seja, cada vez mais testes em menos material. Os pacientes vivem mais, o que exige a revisão de materiais antigos nem sempre disponíveis uma vez que não há obrigatoriedade da manutençáo do bloco de parafina por mais de cinco anos.

Finalmente, a patologia vem enfrentando uma carência no número de patologistas. Esse é um fenômeno mundial... não há patologistas suficientes. Considerando que o Brasil tem cerca de 450.000 médicos em atuação e que os patologistas são em número aproximadamente de 2.500 , chega-se a relação de menos de $0,02 \%$ dos profissionais. Nos Estados Unidos esta cifra é de 1,43\% e há uma queda observada de $17 \%$ nos últimos dez anos ${ }^{17}$. Mais interessante é que dos 569 ingressantes no primeiro ano de residência, apenas 201 (35\%) se formaram nos EUA. 


\section{E QUAIS SÃo AS PERSPECTIVAS NA CHEGADA NA TRILHA NA Patologia de Precisão}

Como discutido, a patologia diagnóstica teve, nos últimos quinze anos, uma mudança radical que foi precedida por uma revolução da prática médica nos vinte anos anteriores. $\mathrm{O}$ mais interessante é que essas mudanças vieram em cima de fundamentos sólidos de diversos séculos. Vivemos um primeiro momento de 300 anos de conhecimento anatômico, seguidos de outros 250 anos de anatomia mórbida, para então entramos por 100 anos de solidificação e correlação dos achados histopatológicos com a prática médica. Nos últimos 40 , passamos a entender os achados histopatológicos dentro do contexto funcional e molecular e, mais recentemente, com a participação na prescrição medicamentosa. Esses tempos encurtados do advento dos biomarcadores e da patologia molecular simplesmente refletem a velocidade da tecnologia aplicada a medicina. Isso traz a pergunta de que se a patologia está obsoleta.

Minha visão é ela está mais viva do que nunca. Há algum tempo, diante de uma biópsia de tumor pulmonar. tínhamos a obrigação de separar um carcinoma não-pequenas células de um carcinoma de pequenas células, na verdade, com pouco ou nenhum efeito prático pois o tratamento era uniforme e a grande maioria dos pacientes chegava em estádio avançado e a média da sobrevida era bem aquém dos 12 meses. Depois da descoberta dos inibidores e de sua aprovação para uso clínico de EGFR em 2003, passou a ser fundamental a separação, dentro do grupo não-pequenas células, dos adenocarcinomas pois estes estavam associados à mutação do $E G F R^{18}$. Outras terapias dirigidas contra alteraçôes genômicas se seguiram em velocidade nunca antes vista, levando a um tratamento mais eficiente que mudou a história natural desta doença ${ }^{19}$. Hoje, quando se faz o diagnóstico de adenocarcinoma de pulmão, o raciocínio do patologista já se transporta às possibilidades terapêuticas associadas a alvo-moleculares adicionais com alteraçôes genômicas nos genes $A L K, R O S$, $M E T, R A S, B R A F, H E R-2$ e à possibilidade do tratamento imunoterápico. Munidos desse conhecimento, podemos interligar as alteraçóes do DNA com a estrutura arquitetural dos tumores, lembrando que, na verdade, o que o patologista vê é a fenocópia dos defeitos genômicos ${ }^{20}$. Isto é fascinante na patologia atual pois abre as perspectivas à importância clínica do diagnóstico correto. Talvez a insistência de praticar e ensinar a patologia como era feito há anos atrás e que as residências insistem em fazer possa levar a uma obsolescência perceptiva. E, se isso não mudar, é o caminho para a obsolescência funcional.

Por consequência, se temos que aprender e aplicar uma nova patologia, não podemos ensiná-la na graduação e na pós- 
graduação da mesma maneira. $\mathrm{O}$ estudante atual de medicina necessita ter um forte conhecimento de biologia celular e molecular (BCM), em pelo menos três momentos de sua formação. Inicialmente, ele deve trazer uma bagagem sólida desta ciência. Infelizmente, o que traz de seu ciclo colegial não é suficiente e temos que apresentar uma BMC detalhada, com conceitos que fiquem enraizados. Vemos uma grande tendência de os cursos atuais exporem os alunos a problemas clínicos precocemente. Cremos que embora isto esteja correto na teoria, a formação básica está sendo relegada no seu momento mais importante. Em um segundo momento, a BCM deve ser inserida no aprendizado dos processos patológicos. Não há como na patologia não estabelecer a relaçáo das alteraçóes genômicas com a sua fenocópia, os aspectos histopatológicos. Continuar ensinando a patologia na insistência do aluno aprender aspectos histopatológicos vai nos perpetuar o pequeno interesse pela patologia pelos estudantes de graduação. Temos que ensinar como os aspectos histopatológicos interagem com as demais disciplinas. E finalmente, o estudante da medicina tem que ter acesso ao novo modo de pensar as terapias associando aos conhecimentos de BCM absorvidos nos outros dois ciclos.

Assim, os programas de residência médica têm que sofrer uma modificação radical. Muito pouco se discute de patologia molecular e muito menos são os médicos residentes expostos aos laboratórios de patologia molecular. Isso ocorre por diversos fatores, entre eles o sucateamento dos departamentos de patologia clássicos que não tem acesso a essas técnicas. Mas também porque os preceptores médicos estão defasados pela própria formação e necessitam de uma ampla reciclagem. Por vezes, até o acesso à imuno-histoquímica é restrito. E mesmo quando há o acesso, se ensina qual antígeno está presente em cada tumor, mas não se discute a natureza do anticorpo, os detalhes moleculares, as variantes genômicas ou racionalidade no uso. Transportando para a prática clínica, é como receitar o remédio sem conhecer a farmacologia e interaçôes que estão por detrás daquela indicação.

O patologista não pode mais trabalhar em um laboratório isolado e deve sempre estar em um time multidisciplinar. Não há mais lugar para que a participação seja restrita a emitir um laudo descritivo sem que haja uma integração dos resultados morfológicos, dos biomarcadores e as alteraçóes moleculares. Hoje ele precisa estar atento ao desenvolvimento da indústria farmacêutica, pois as novas drogas estão, em sua indicação, quase que invariavelmente ligadas a um biomarcador. Com o advento dos ensaios clínicos em cesta ("basket trials") onde os tumores não são selecionados por tipo histológico ou topografia primária, mas sim pela alteraçáo genômica, à qual a droga agnóstica está indicada. Não muito tempo atrás, a patologia 
diagnóstica e a farmacologia não tinham intersecção, mas hoje caminham ombro a ombro. O patologista é obrigado a participar dos programas de educação continuada de diversas disciplinas para entender o seu papel no time multidisciplinar.

\section{Conclusão}

Como abordamos na trilha que seguimos, a patologia sofreu profundas modificações ao longo deste caminho. Chega a primeira parte do século XXI viva e mudando seu papel na jornada do paciente. Entender esse momento é crucial para que a patologia não se torne obsoleta e consiga resgatar o interesse dos estudantes e egressos da medicina. Sem que se mude a abordagem no curso médico, demonstrando para o acadêmico a sua importância clínica, teremos uma consequência extremamente grave para a nossa prática, relegando o patologista a um segundo plano completamente indesejável. A ponte entre os achados genômicos e sua tradução clínica pode e deve ser construída pela patologia, com uma abordagem morfo-funcional atual. A trilha foi longa, mas o caminho que se abre no momento é fascinante.

\section{REFERÊNCIAS BibLIOGRÁFICAS}

1. Ghosh S: Human Cadaveric dissection: a historical account from ancient Greece to the modern era. Anat Cell Biol 2015; 48:153-169.

2. Somerville R: Pope Alexander III and the Council of Tours (1163). A study of ecclesiastical politics and institutions in the twelfth century. Berkeley, CA 1977; The University of California Press.

3. Carr I: The lesion. http://medheritage. lib.umanitoba.ca/?page_id=424.

4. Romero-Reverón R: Marcello Malpighi (1628-1694), founder of microanatomy. Int J Morphol 2011: 399-402.

5. Gal AA: In search of the origins of modern surgical pathology. Adv Anat Pathol 2001; 8:1-13.

6. Burke FV: The $\mathrm{pH}$ of formalin - a factor in fixation. Am J Pathol 1933; 9:915-920.

7. Titford M: The long history of hematoxylin. Biotech Histochem 2005; 80:73-78.

8. https://www.nobelprize.org/prizes/ medicine/1906/summary/ 
9. Tan SY, Brown J: Rudolph Virchow (1821-1902): Pope of pathology. Singapore Med J 2006; 47(7):567-568.

10. Editorial: Rudolph Virchow (18211902) - Anthropologist, Archeologist, Politics, and Pathologist. Jama 1964: 188:1080-1081.

11. Svajdler M, Svajdler P: Frozen Section: history, indications, contraindications and quality assurance. Cesk Patol Summer; 2018:54:58-62.

12. Pai-Dhungat P: Invention of Electronic Microscope. J Assoc Physicians India 2020; 68:93.

13. Strimbu K, Tavel JA: What are biomarkers? Curr Opin HIV AIDS 2010; 5:463-466.

14. Selleck MJ, Senthil M, Wall NR. Making meaningful clinical use of biomarkers. Biomark Insights 2017: 12:1177271917715239.

15. Nalejska E, Maczynska E, Lewandowska MA: Prognostic and Precitive biomarkers: tools in personalized Medicine. Mol Diag Ther 2014; 18:273-284.
16. Wang K, Lee I, Carlson G, Leroy H, Galas D: System biology and discovery of diagnostic biomarkers. Dis Markers 2010; 199-207.

17. Lundberg GD:L How many pathologists does the United States need? Jama Netw Open. 2019; 2(5):e194308.

18. Lynch TJ, Bell DW, Sordella R, Gurubhagavatula S, Okimoto RA, Brannigan BW et al.: Activating mutations in the Epidermal Growth Factor Receptor underlying responsiveness of non-small-cell lung cancer to gefitinib. New Engl J Med 2004; 350:2129-2139.

19. Saito M, Suzuki H, Kono K, Takenoshita S, Kohno T: Treatment of lung adenocarcinoma by moleculartargeted therapy and immunotherapy. Surg Today 2018; 48:1-8.

20. Caso R, Sanchez-Vega F, Tan ST, Mastrogiacomno B, Zhou J, Jones GD et al.: The underlying tumor genomics of predominant histologic subtypes in lung carcinoma. J Thorac Oncol 2020; S1556-0864(20)30636-5. 